\title{
Traditional and microirrigation with stochastic soil moisture
}

\author{
Giulia Vico ${ }^{1}$ and Amilcare Porporato ${ }^{1,2}$ \\ Received 16 April 2009; revised 21 September 2009; accepted 13 October 2009; published 9 March 2010.
}

[1] Achieving a sustainable use of water resources, in view of the increased food and biofuel demand and possible climate change, will require optimizing irrigation, a highly nontrivial task given the unpredictability of rainfall and the numerous soil-plantatmosphere interactions. Here we theoretically analyze two different irrigation schemes, a traditional scheme, consisting of the application of fixed water volumes that bring soil moisture to field capacity, and a microirrigation scheme supplying water continuously in order to avoid plant water stress. These two idealized irrigation schemes are optimal in the sense that they avoid crop water stress while minimizing water losses by percolation and runoff. Furthermore, they cover the two extremes cases of continuous and fully concentrated irrigation. For both irrigation schemes, we obtain exact solutions of the steady state soil moisture probability density function with random timing and amounts of rainfall. We also give analytical expressions for irrigation frequency and volumes under different rainfall regimes, evaporative demands, and soil types. We quantify the excess volumes required by traditional irrigation, mostly lost in runoff and deep infiltration, as a function of climate, soil, and vegetation parameters.

Citation: Vico, G., and A. Porporato (2010), Traditional and microirrigation with stochastic soil moisture, Water Resour. Res., 46, W03509, doi:10.1029/2009WR008130.

\section{Introduction}

[2] Globally, irrigated agriculture is the primary user of freshwater, accounting for nearly $85 \%$ of total water consumption [Jury and Vaux, 2007], and provides about $40 \%$ of the total food production [Fereres and Soriano, 2007]. Agriculture-related water demand is expected to increase in the near future, in face of foreseen alterations of rainfall regime due to climate change, and increased food, fiber and biofuel demands. Irrigation scheduling is part of the complex problem of water resource management and optimization [English et al., 2002]. On the one hand, sustainable irrigation must harmoniously balance the concurring water demands for industrial and municipal uses with the requirements of natural ecosystems. Hence, there is an increasing need, especially in water-limited regions, to minimize the amount of irrigation water per cultivated area. On the other hand, farmers are interested in maximizing profits, through balancing crop yields and irrigation costs, by adapting water applications to plant water requirements, and water resources managers must know in advance the water demand for agriculture to allocate water and plan long-term investments for infrastructure and its maintenance. These tasks, however, are highly complicated by rainfall intermittency and unpredictability.

\footnotetext{
${ }^{1}$ Department of Civil and Environmental Engineering, Duke University, Durham, North Carolina, USA.

${ }^{2}$ Visiting professor at Laboratory of Environmental Fluid Mechanics and Hydrology, School of Architecture Civil and Environmental Engineering, École Polytechnique Fédérale de Lausanne, Lausanne, Switzerland.
}

Copyright 2010 by the American Geophysical Union 0043-1397/10/2009WR008130\$09.00
[3] Irrigation has the function of supplementing natural rainfall, either to meet crop water requirements (i.e., to avoid plant water stress and the ensuing reduction in crop yield and/or quality) or to maintain a limited stress level (i.e., deficit irrigation [Chalmers et al., 1981]). We will focus here on stress avoidance irrigation, hence aiming at crop yield maximization under an optimal irrigation. Ideally, unless time scheduling constrains are present, or in case of reduced water availability, water applications should be done just before soil moisture hits the stress level. This level can be reasonably associated to the soil moisture corresponding to incipient stomatal closure, $s^{*}$ [Hsiao, 1973; Porporato et al., 2001]. Sometimes a minimal stress level (deficit irrigation) may be acceptable when water supply is limited [English, 1990] and/or expensive, or even desirable for quality purposes for specific products such as some fruit trees and vines [Fereres and Soriano, 2007, and references therein]. In any case, an optimal irrigation schedule requires the determination of the right amount and timing of water supplement, on the basis of soil water balance calculations or by directly tracking soil moisture and plant water status [Jones, 2004].

[4] In this work, we analyze theoretically two forms of demand-based irrigation, and compare them in terms of total water volumes and frequency under conditions of stochastic rainfall variability. The most traditional demand-based irrigation typically consists of repeated, massive but infrequent applications of water that fill the root zone up to field capacity (loosely defined here as the point where drainage from the root zone becomes significant) by furrow, flood or sprinkler irrigation. Conversely, modern irrigation principles advocate a more finely tuned irrigation realized by means of microirrigation techniques (e.g., drip or trickle irrigation, microsprinklers, microsprayers, or subsurface emitters [Hillel, 2004]), in which water is supplied continuously to avoid 
water stress, while minimizing runoff and percolation losses. This also results in reduced leaching of soluble chemicals (e.g., pesticides and fertilizers [Böhlke, 2002]), although it may also increase the risk of soil salinization [Bras and Seo, 1987] or reduce recharge to groundwater and streams [English et al., 2002].

[5] The two irrigation schemes are idealized as follows: (1) a modern microirrigation scheme with continuous supply of water which maintains the root zone soil moisture just above the stress level until the next rainfall event and (2) a traditional irrigation scheme, consisting in concentrated applications of water, when soil moisture reaches the same stress level, that bring soil moisture back to field capacity. These two idealized irrigation schemes are optimal in the sense that they avoid crop water stress while minimizing water losses by percolation and runoff. Furthermore, they cover the two extremes cases of continuous and fully concentrated irrigation. More general irrigation schemes, including deficit irrigation, will be analyzed in further contributions.

[6] We consider both random timing and amounts of rainfall, and physically model the processes in the soil-plant system at the daily level. Such a time scale is intermediate between the subdaily scale of farm level irrigation models (e.g., California Irrigation Management Information System) and the seasonal scale of models used to quantify growing season irrigation needs [e.g., English et al., 2002, and references therein] for long-term and regional-scale planning. Our approach accounts in a parsimonious way for the main climate, soil and vegetation characteristics, and includes the most important source of uncertainty in soil moisture variability (i.e., rainfall) with a stochastic approach. The soil moisture model used here builds upon previous stochastic soil moisture models employed in ecohydrology [Rodriguez-Iturbe and Porporato, 2004; Rodriguez-Iturbe et al., 1999]. We assume that plant productivity is not nutrient limited and do not discuss salinity problems. Moreover, we only consider statistically steady state conditions for time-homogeneous vegetation and climatic conditions during the growing season, as discussed below. Within the vast literature on irrigation, the analytical solutions presented here provide a valuable alternative to the fully numerical optimization schemes that include the effect of stochastic rainfall variability [see, e.g., Bras and Cordova, 1981; Georgiou and Papamichail, 2008; Protopapas and Georgakakos, 1990; Zhang and Oweis, 1999, and references therein], in that they clearly show the impact of the main soil, vegetation and climate characteristics on irrigation requirements.

\section{Model Formulation}

[7] Assuming negligible lateral soil moisture fluxes, the water balance averaged over the root zone reads

$$
n Z_{r} \frac{d s(t)}{d t}=R(t)+I(s(t))-E T(s(t))-L Q(s(t))
$$

where $n$ is the soil porosity, $Z_{r}$ is the active soil depth (where most of the roots are located), $s$ is the relative soil moisture, $s=\left(\theta-\theta_{r}\right) / n$, with $\theta$ volumetric soil moisture and $\theta_{r}$ the residual water content (here assumed to coincide with wilting point for simplicity). Hence $s$ represents here the plant-accessible water (with $\theta_{r} / n$ ranging between 0.08 and 0.19 for loamy sand and loam, respectively [Laio et al., 2001]).

[8] The inputs to the soil moisture balance are rainfall, $R(t)$, and irrigation, $I(s(t))$. Rainfall is modeled as instantaneous events occurring according to a marked Poisson process of rate (mean frequency of rainfall events) $\lambda$, and with exponentially distributed depths with mean $\alpha$ [Rodriguez-Iturbe and Porporato, 2004; Rodriguez-Iturbe et al., 1999]. $R(t)$ may be purged of canopy interception, which reduces both the frequency of effective rainfall and its depth [Daly et al., 2008; Rodriguez-Iturbe et al., 1999]. Accordingly, rainfall process is censored, $\lambda^{\prime}=\lambda e^{-\Delta / \alpha}$, where $\Delta$ is the crop-dependent rainfall depth threshold below which no rainfall reaches the ground [Rodriguez-Iturbe et al., 1999], and the mean rainfall depth is reduced as $\alpha^{\prime}=$ $\kappa \alpha$ [Daly et al., 2008]. Irrigation is a state-dependent input as its timing and amount typically depend on soil moisture status, according to the two different schemes described in section 1.

[9] The main soil water losses are accounted for in equation (1): $E T(s(t))$ is the rate of loss of soil moisture due to evapotranspiration (ET), while $L Q(s(t))$ combines deep infiltration and runoff losses. Daily ET is assumed to vary in time only through soil moisture. For simplicity, the impacts of day-to-day variability on transpiration rate (chiefly due to changes in air temperature and humidity, and solar radiation) will be neglected here. They could be included using the approach of Daly and Porporato [2006a], but tend to have a secondary effect compared to rainfall. Plant growth and changes in leaf area index may be more relevant for ET, in particular when annual crops are considered. Nevertheless, to keep analytical tractability, the dependence of transpiration rate on soil moisture, $\operatorname{ET}(s(t))$, will be assumed to be time invariant, and interpreted as an average value over the growing season. Hence, our model results are more readily applicable to perennial crops and to cases where higher soil water evaporation at the beginning of the season offsets the lower transpiration due to low leaf area index. Deep infiltration and runoff losses, $L Q(s(t))$, are also treated here in a simplified manner, as they were by Milly [2001] and Porporato et al. [2004]. Accordingly, they are assumed to take place instantaneously (at the daily time scale) whenever soil moisture reaches a threshold $s_{1}$, typically around soil field capacity or slightly above it. Thus, when (effective) rainfall exceeds the available storage capacity, $n Z_{r}\left(s_{1}-s\right)$, any excess is immediately lost as runoff and deep infiltration. In vegetated ecosystems and in agricultural fields, where the mechanism of rainfall excess runoff production is dominant and soil tends to be well drained, this assumption, which allows analytical tractability, is quite realistic [see also Rigby and Porporato, 2006]. While for most of the analytical results reported below the specific form of $E T(s(t))$ is not important, the quantitative applications of section 3 employ a piecewise linear dependence on soil moisture [Rodriguez-Iturbe and Porporato, 2004; Rodriguez-Iturbe et al., 1999]. Especially for monocultures [e.g., Kalapos et al., 1996; Morison and Gifford, 1984], in fact, empirical evidence shows a roughly linear dependence of ET on soil moisture from basically zero at wilting point (here $s=0$ ) up to a maximum rate $E_{\max }$ at the point of incipient stomatal closure $\left(s^{*}\right)$, and then constant and equal to $E_{\max }$ for higher soil moisture values (i.e., under well watered conditions). $E_{\max }$ depends on type of plant, soil and 


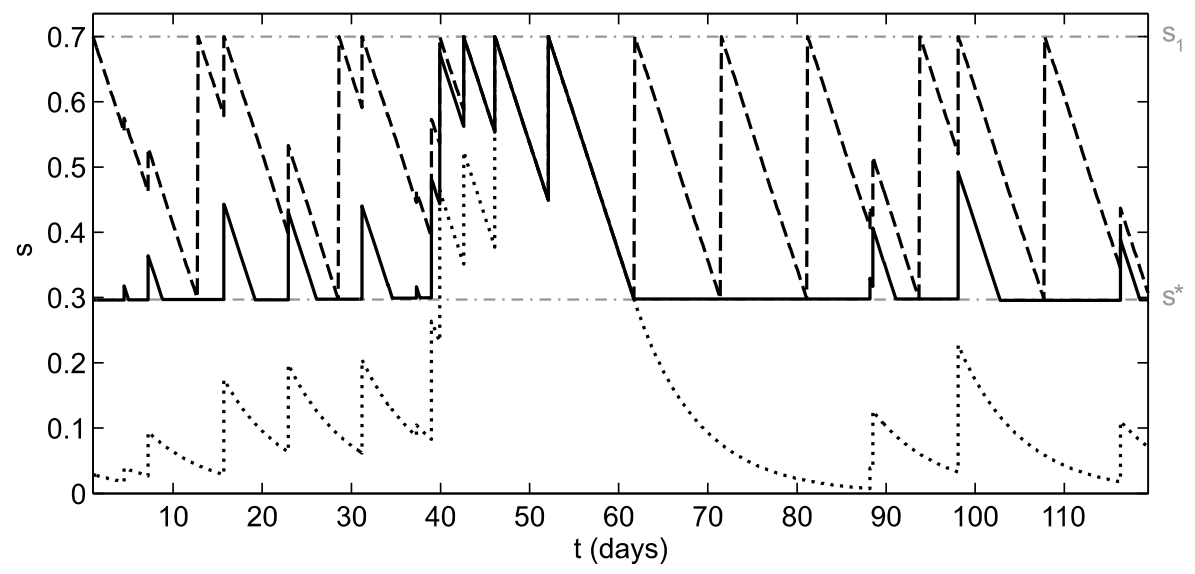

Figure 1. Example of soil moisture time series for rain-fed agriculture (short-dashed line), microirrigation (solid line), and traditional irrigation (long-dashed line). Soil is sandy loam, with $n=0.43, Z_{r}=25 \mathrm{~cm}$ [Rodriguez-Iturbe and Porporato, 2004], $s^{*}=0.3$, and $s_{1}=0.7$. Average precipitation depth is $\alpha=$ $15 \mathrm{~mm}$ and rainfall frequency $\lambda=0.15$ day $^{-1}$, with interception parameters $\Delta=1 \mathrm{~mm}$ and $\kappa=0.9$. Evapotranspiration rate is $E_{\max }=0.45 \mathrm{~cm} \mathrm{~d}^{-1}$. As a reference, $s^{*}$ and $s_{1}$ are indicated by horizontal dashdotted lines.

climate, and can be estimated using the Penman-Monteith equation [Rodriguez-Iturbe and Porporato, 2004] or available experimental data. Introducing $\eta=E_{\max } /\left(n Z_{r}\right)$, the loss function is thus

$$
\rho(s)= \begin{cases}\eta \frac{s}{s^{*}}, & 0 \leq s<s^{*} \\ \eta, & s^{*} \leq s \leq s_{1} .\end{cases}
$$

The mean rainfall depth will also be normalized by $n Z_{r}$, as $\gamma=\alpha^{\prime} / n Z_{r}$.

[10] The water balance in equation (1) will be used to investigate the impact of the two irrigation schemes on the soil moisture probability distribution at steady state, and the requirements of such schemes in terms of irrigation frequency and water volumes. Both irrigation schemes are assumed to be activated when the onset-of-stress threshold $s^{*}$ is reached (stress avoidance irrigation). As a term of comparison, the case of rain-fed agriculture (i.e., no irrigation) will be discussed first. The salient features of the three different cases are readily apparent from the examples of Figure 1, where numerically generated soil moisture time series under the two schemes are compared, along with rainfed agriculture, for the piecewise linear loss function (equation (2)).

\subsection{Rain-Fed Agriculture (No Irrigation)}

[11] In the absence of irrigation, the previous nonlinear stochastic differential equation for the soil water balance, describing the soil moisture evolution at the daily time scale, has been extensively analyzed in previous contributions [Rodriguez-Iturbe and Porporato, 2004, and references therein]. Figure 1 (short-dashed line) shows a numerically generated realization of the stochastic soil moisture process during a growing season: plants are water stressed whenever soil moisture is below the point of incipient stomatal closure, $s^{*}$. The evolution of the probability density function (pdf) of soil moisture for $0<s \leq s_{1}$ is described by the master or differential Chapman-Kolmogorov equation (see
Appendix A for details [Rodriguez-Iturbe and Porporato, 2004; Rodriguez-Iturbe et al., 1999]). Since a general solution of the master equation presents serious mathematical difficulties, we focus here on the case of stochastic steady state conditions, i.e., $\partial p(s, t) / \partial t=0$. Under such a hypothesis, the following pdf of soil moisture is obtained as described in Appendix A:

$$
p(s)=\frac{C}{\rho(s)} \exp \left(-\gamma s+\lambda^{\prime} \int_{s^{*}}^{s} \frac{d u}{\rho(u)}\right),
$$

where $0<s \leq s_{1}, C$ is a normalizing constant and $\rho(s)$ is a generic normalized ET function. Note that the lower boundary of the integral inside the exponential can be absorbed in the normalization constant $C$ and it is thus arbitrary.

\subsection{Continuous Irrigation (Modern Microirrigation)}

[12] With the microirrigation typical of modern intensive agriculture, irrigation is turned on when soil moisture reaches the onset-of-stress level $s^{*}$. The rate of irrigation is such that soil moisture is maintained constant and equal to $s^{*}$ until the next (effective) rainfall event takes place. Water application rate is therefore constant and equal to the evapotranspiration losses at $s^{*}$, i.e., $I_{m}=E T\left(s^{*}\right)=n Z_{r} \rho\left(s^{*}\right)$ (the quantities referring to microirrigation will be indicated with a subscript $m$ hereafter). An example of the typical time evolution of soil moisture for this irrigation scheme is illustrated in Figure 1 with solid line. Since soil moisture stays for a finite time at the prescribed level $s^{*}$, the soil moisture pdf is of the mixed type, with an atom of probability, $p_{0}$, at $s^{*}$, and a continuous part, $p_{m}(s)$, for $s^{*}<s \leq s_{1}$ [Cox and Miller, 2001].

[13] Apart from a multiplication constant, the master equation describing the evolution of soil moisture pdf for microirrigation (equation (A6)) admits the same solution as the master equation relative to rain-fed agriculture (equation (A1)). In fact, as also seen intuitively comparing solid line to the short-dashed one in Figure 1, the relative 
fraction of time spent by the process between any two soil moisture levels is not changed by the presence of the atom of probability in $s^{*}$. This fact implies that only the normalization constant is changed. Hence, the continuous part of the pdf for $s^{*}<s \leq s_{1}$ reads

$$
p_{m}(s)=\frac{C_{m}}{\rho(s)} \exp \left(-\gamma s+\lambda^{\prime} \int_{s^{*}}^{s} \frac{d u}{\rho(u)}\right),
$$

while the atom of probability at $s^{*}$ is

$$
p_{0}=\frac{C_{m}}{\lambda^{\prime}} e^{-\gamma s^{*}}
$$

where $C_{m}$ is the normalization constant (see Appendix A for details).

\subsection{Concentrated Applications (Traditional Irrigation)}

[14] Traditional irrigation typically foresees the concentrated delivery (instantaneous, at the daily time scale) of fixed water volumes when soil moisture reaches $s^{*}$. A numerically generated realization of the stochastic soil moisture process is shown in Figure 1 (long-dashed line). The applied amount of water is such that soil moisture is brought to $s_{1}$ (or slightly higher in case of salinity control). While this form of irrigation may be less efficient than microirrigation (see section 3), it is an optimal scheme among the ones that use concentrated applications, and it is always more effective than fixedschedule irrigation. According to this scheme, the soil moisture process jumps to $s_{1}$ with probability 1 , whenever it reaches $s^{*}$ during a dry down.

[15] As shown in Appendix A, the pdf of soil moisture for traditional irrigation for generic ET losses $\rho(s)$ becomes

$$
\begin{aligned}
p_{t}(s)=-C_{t} \frac{\exp \left(-\gamma\left(s-s^{*}\right)+\lambda^{\prime} \int_{s^{*}}^{s} \frac{d u}{\rho(u)}\right)}{\rho(s)} \\
\cdot\left[1+\gamma \int_{s^{*}}^{s} \exp \left(\gamma\left(u-s^{*}\right)-\lambda^{\prime} \int_{s^{*}}^{u} \frac{d y}{\rho(y)}\right) d u\right],
\end{aligned}
$$

where $C_{t}$ is the normalization constant (the quantities referring to traditional irrigation will be indicated with a subscript $t$ hereafter).

\subsection{Irrigation Frequency and Volumes}

[16] The irrigation requirements over the growing season in terms of average frequency and water volumes may be obtained from the crossing properties of the soil moisture process. The frequency and durations of the excursions of the soil moisture process below and above a generic threshold $s=\xi$ have been obtained before [Porporato et al., 2001; Rodriguez-Iturbe and Porporato, 2004]. The frequency of downcrossings is

$$
\nu_{\xi}^{\downarrow}=\rho(\xi) p(\xi),
$$

which at steady state equals the frequency of upcrossings. The mean time between a downcrossing and the subsequent upcrossing (i.e., the time spent by the process below the same threshold) is

$$
\bar{T}_{\xi}^{\downarrow}=\frac{P(\xi)}{\rho(\xi) p(\xi)}
$$

where $P(\xi)$ is the cumulative probability function (equation (A5)). The time spent by the process above the threshold follows from equation (8) as

$$
\bar{T}_{\xi}^{\uparrow}=\frac{1-P(\xi)}{\rho(\xi) p(\xi)} .
$$

For rain-fed agriculture the frequency of downcrossing of the threshold $\xi=s^{*}$ and the time spent by the process below the same threshold offers valuable indications on plant water stress [Porporato et al., 2001].

[17] Regarding the microirrigation scheme, the fraction of time in which irrigation is performed equals the fraction of time spent by the process at $s^{*}$, i.e., the atom of probability $p_{0}$. Since during this time irrigation rate balances ET, the volume per unit area needed for microirrigation in a growing season of duration $T_{\text {seas }}$ is

$$
V_{m}=n Z_{r} \rho\left(s^{*}\right) p_{0} T_{\text {seas }} .
$$

The frequency and durations of irrigation may be derived from the crossing properties of the process (equations (7)(9)), with threshold $\xi=s^{*}$. Hence, the mean frequency of irrigation is

$$
\nu_{m}=\lambda^{\prime} p_{0}
$$

and the average number of irrigation occurrence during the growing season is $\lambda^{\prime} p_{0} T_{\text {seas }}$. Similarly to equation (8), the mean duration of each microirrigation treatment (i.e., the time between the initiation of the irrigation treatment and the occurrence of the following effective rainfall event) is

$$
\bar{T}_{s^{*}, m}^{\downarrow}=\frac{P_{m}\left(s^{*}\right)}{\rho\left(s^{*}\right) p_{m}\left(s^{*}\right)}=\frac{p_{0}}{\lambda^{\prime} p_{0}}=\lambda^{\prime}-1
$$

in agreement with the memoryless property of the Poisson process (the second equality follows from balance of upcrossings and downcrossings, and from equation (A8)). In fact, since rainfall events occur according to a Poisson process, their interarrival times are exponentially distributed. It follows that the residual time to the next rainfall event has the same distribution of the rainfall events, regardless of the moment in which the microirrigation application is initiated [Cox and Miller, 2001]. Thus the expected time before the next (effective) rainfall event is the average storm interarrival time, i.e., $\lambda^{\prime-1}$, which also represents the mean duration of each microirrigation treatment. The mean time during which no irrigation is applied is

$$
\bar{T}_{s^{*}, m}^{\uparrow}=\frac{1-P_{m}\left(s^{*}\right)}{\rho\left(s^{*}\right) p_{m}\left(s^{*}\right)}=\frac{1-p_{0}}{\lambda^{\prime} p_{0}} .
$$



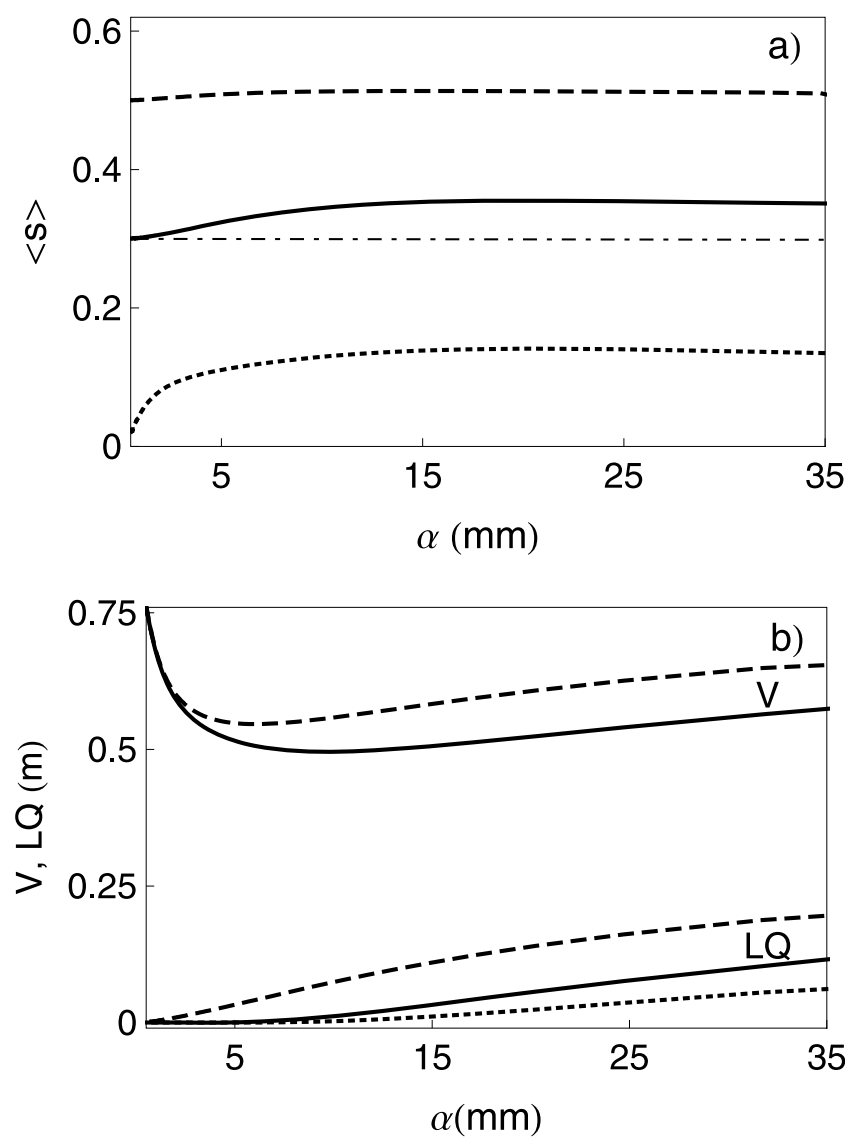

Figure 2. (a) Average soil moisture and (b) long-term soil water balance for fixed total growing season rainfall depth $\left(R_{\text {tot }}=400 \mathrm{~mm}\right)$ and variable $\lambda$ and $\alpha$, for rain-fed agriculture (short-dashed lines), microirrigation (solid lines), and traditional irrigation (long-dashed lines). In Figure $2 \mathrm{a}$ the dash-dotted line represents $s^{*}$. In Figure 2b, irrigation volumes, $V$, are compared to deep percolation and runoff losses, $L Q$ (short-dashed line refer to $L Q$ for rain-fed agriculture). The components of the water balance are expressed as volumes per unit area, i.e., depths. The growing season duration, $T_{\text {seas }}$, is assumed to be 180 days; all the other parameters are as in Figure 1.

[18] In contrast, for the traditional irrigation, the frequency of irrigation treatments is the same as the frequency of downcrossings of $s^{*}$, since arriving at $s^{*}$ always triggers an irrigation application. In other words, the probability of an effective rainfall event at $s=s^{*}$ is $\lambda^{\prime} d t$ while that of irrigation is 1 , so that the infinitesimal frequency of upcrossings due to rainfall does not contribute to the overall frequency. Hence, the frequency of traditional irrigation is

$$
\nu_{t}=\rho\left(s^{*}\right) p_{t}\left(s^{*}\right)
$$

In terms of irrigation volumes, each irrigation treatment supplies a volume (per unit area) $n Z_{r}\left(s_{1}-s^{*}\right)$. The total volume needed during a growing season is given by the volume of the single treatment $\left(n Z_{r}\left(s_{1}-s^{*}\right)\right)$ multiplied by the number of applied treatments $\left(\nu_{t} T_{\text {seas }}\right)$, that is

$$
V_{t}=n Z_{r}\left(s_{1}-s^{*}\right) \rho\left(s^{*}\right) p_{t}\left(s^{*}\right) T_{\text {seas }} .
$$

The mean time between treatments is equal to the average time spent by the process above $s^{*}$

$$
\bar{T}_{s^{*}, t}^{\uparrow}=\frac{1}{\rho\left(s^{*}\right) p_{t}\left(s^{*}\right)},
$$

which follows from equation (9), considering that $P_{t}\left(s^{*}\right)=0$.

[19] The irrigation volume expressions, equations (10), (15), coupled with the analytical pdf solutions (5) and (6), are the key result of this work. These allow to determine the difference in water requirements between the two irrigation schemes as a function of soil, plant and climatic conditions, i.e.,

$$
V_{t}-V_{m}=n Z_{r} \rho\left(s^{*}\right) T_{\text {seas }}\left[\left(s_{1}-s^{*}\right) p_{t}\left(s^{*}\right)-p_{0}\right] .
$$

\section{Comparison of Irrigation Requirements for Traditional and Microirrigation}

[20] The previous analytical descriptions allow us to compare the irrigation requirements of the two idealized irrigation schemes, as well as to analyze their dependence on the main crop, soil and hydroclimatic parameters. In particular, assuming the piecewise linear loss function in equation (2), it becomes possible to identify the crop ( $E_{\max }$, $\left.s^{*}, Z_{r}\right)$ and soil $\left(s_{1}, s^{*}, n\right.$ and $\left.Z_{r}\right)$ features that result in the most sustainable and profitable irrigation scheme under given climatic conditions.

[21] A sensitivity analysis (not shown) suggested that, for realistic values of the parameters, maximum transpiration rate, $E_{\max }$, and rainfall statistics, $\alpha$ and $\lambda$, are the main drivers of irrigation needs, followed by the interception parameters, while the incipient stress point, $s^{*}$, and soil features tend to play a secondary role.

\subsection{Mean Soil Moisture Balance and Irrigation Volumes}

[22] Mean soil moisture $\langle s\rangle$ can be easily computed from the analytical soil moisture pdf's (Appendices A and B). As expected, microirrigation maintains the mean soil moisture closer to $s^{*}$ than any other treatment, but always above it (Figure 2a, solid line), thus guaranteeing minimum water use while avoiding plant water stress. Traditional irrigation tends to maintain higher mean soil moisture, while for rainfed agriculture the mean can be below stress for low total rainfalls. $\langle s\rangle$ is not significantly impacted by mean event depth, except at very low values of $\alpha$, when effective rainfall is minimal due to interception and $\langle s\rangle$ goes to zero for rainfed agriculture and to $s^{*}$ for microirrigation (Figure 2a).

[23] The long-term mean soil water balance is of the greatest interest, as it provides a solution for the water volumes needed for irrigation and the percolation losses. The former ones are obviously related to irrigation costs and environmental impact, while the latter also allow one to quantify leaching of soluble chemicals and soil salts, as well as groundwater recharge.

[24] The different components of the water balance are the long-term averages of the respective components of 
the soil moisture balance at the daily time scale (equation (1)), i.e.,

$$
\left\langle R^{\prime}\right\rangle+\langle I\rangle=\langle E T\rangle+\langle L Q\rangle
$$

The inputs to the system are rainfall (minus interception), $\left\langle R^{\prime}\right\rangle=\alpha^{\prime} \lambda^{\prime}$, and average daily irrigation, $\langle I\rangle$. Depending on the adopted irrigation scheme, the latter can be obtained from equations (10) or (15) coupled with equations (5) and (6), respectively. Total input is partitioned into evapotranspiration, $\langle E T\rangle=\int_{0}^{s_{1}} \rho(u) p(u) d u$, and runoff and deep infiltration losses, $\langle L Q\rangle^{0}$, which may be estimated by difference from equation (18). Considering the soil water balance for a growing season of duration $T_{\text {seas }}$, the total rainfall is $R_{\text {tot }}=\alpha \lambda T_{\text {seas }}$ (resulting in a total effective rainfall input $\left.R_{\text {tot }}^{\prime}=\alpha^{\prime} \lambda^{\prime} T_{\text {seas }}\right)$, irrigation volume is $\langle I\rangle T_{\text {seas }}$, i.e., $V_{m}$ or $V_{t}$ (equations (10) and (15), respectively), and water losses by runoff and percolation are $L Q=\langle L Q\rangle T_{\text {seas }}$. Note that water volumes are expressed in terms of volumes per unit area, i.e., depths.

[25] With constant evapotranspiration function above $s^{*}$ (equation (2)), the same amount of water is transpired by crops subjected to either irrigation scheme, as both of them maintain soil moisture above the onset-of-stress level (Figure 2a). Hence, a comparison of long-term soil water balances relative to the two irrigation schemes suggests that the difference between the mean soil water balances of micro- and traditional irrigation is totally compensated by the difference in deep percolation and runoff, i.e.,

$$
V_{t}-V_{m}=L Q_{t}-L Q_{m}
$$

Under realistic soil evaporation parameters, $V_{t}-V_{m} \geq 0$, i.e., the microirrigation scheme always requires smaller volumes of water than traditional irrigation. Hence, traditional irrigation also results in higher losses to deep infiltration and runoff than microirrigation.

[26] Figure 2b compares required irrigation volumes to losses by runoff and deep percolation under different rainfall timing (fixed total rainfall amount, with increasing $\alpha$ and decreasing $\lambda$ ). Both irrigation schemes exhibit an increase in irrigation water requirements with increasing mean event depth, with the exception of very small rainfall depths. For small event depths, interception by crop significantly decreases effective rainfall, thus enhancing water demand and reducing runoff and deep infiltration. At the other extreme (large $\alpha$ ), more water is lost to runoff or deep percolation compared to the case of frequent and small events, thus requiring larger irrigation volumes. At intermediate event depths, a minimum of the irrigation volumes is found, occurring for $\alpha$ values which depend on the adopted irrigation scheme (slightly higher $\alpha$ for microirrigation than traditional irrigation, as apparent also from Figure 2b). As expected, even microirrigation results in higher water losses than rain-fed agriculture (Figure 2b compare solid lines to short-dashed ones). In fact, at higher average soil moistures it is more likely that a rainfall event exceeds the soil storage capacity $n Z_{r}\left(s_{1}-s\right)$, which also explains why in turn water lost under traditional irrigation is the highest. Conversely, an increase in event frequency but constant event depth (i.e., increasing total seasonal rainfall) would result in lower required water volumes but larger losses to interception, and runoff and deep infiltration (not shown).

[27] Irrigation volumes not only depend on the rainfall forcing but also on crop and soil features. As expected, higher crop transpiration rates, $s^{*}$ or canopy interception (i. e., higher leaf area index) result in larger water requirements for both irrigation schemes (not shown). The impact of the soil type is more complex, and mainly determined by the deep percolation and runoff losses. Consequently, soil types with higher field capacity (and hence $s_{1}$ ) require smaller irrigation volumes (and less frequent treatments). For similar reasons, deeper active soils (i.e., higher $Z_{r}$ ) tend to have smaller irrigation needs, particularly for traditional irrigation. It is also interesting to analyze the combined effect of the soil thresholds on water requirements. For microirrigation, the decrease of water requirements with increasing field capacity and its increase with increasing stress level balance out when the difference $s_{1}-s^{*}$ is kept constant. This fact has significant implications concerning possible soil amendments for better water use. In fact, since both soil thresholds tend to decrease with increasing soil particle size, an addition of sand or loam may not alter microirrigation requirements as significantly as it might be expected. This is clearly not the case for rain-fed agriculture or traditional irrigation, for which higher $s^{*}$ and $s_{1}$ result in lower average soil moisture levels and higher irrigation demands.

[28] As discussed above, microirrigation requires smaller water volumes than traditional irrigation, as less water is lost to runoff and deep infiltration. Nevertheless, the extent of the water savings by choosing microirrigation (i.e., $V_{t}-V_{m}$ ) depends on hydroclimatic conditions, soil and plant characteristics. The role of rainfall regime and plant water requirements (i.e., those parameters to which irrigation volumes are more sensitive) is explored in Figure 3 (Figures $3 a$ and $3 \mathrm{~b}$, respectively). Regarding rainfall amount and timing, the benefits of microirrigation are largest for medium to high $R_{\text {tot }}$, in particular when rainfall occurs in large storms (Figure 3a). In fact, such rainfall patterns enhance water lost to runoff and deep infiltration (in particular in the case of traditional irrigation), thus also maximizing the difference $V_{t}-V_{m}$ (see equation (19)). The difference in required water volumes for micro- and traditional irrigation is higher when considering crops (and environmental conditions) with higher water demands, both in terms of maximum transpiration rate and point of incipient stomatal closure $s^{*}$ (Figure $3 \mathrm{~b}$ ). However, $V_{t}-V_{m}$ is more sensitive to $E_{\max }$ than to $s^{*}$ : this fact implies that any environmental condition that enhances transpiration rate (e.g., an increase in air temperature or decrease in air humidity) may further favor microirrigation. The advantages of microirrigation could be even more significant if evaporation associated to massive water applications typical of traditional irrigation (or crop interception for sprinkler irrigation) were included.

\subsection{Frequency of Irrigation}

[29] While required volumes are crucial for water allocation and irrigation sustainability, frequency and duration of each irrigation treatment may be relevant for water infrastructure planning and irrigation management. For traditional irrigation, the frequency of irrigation completely defines the process, while for microirrigation, both frequency 

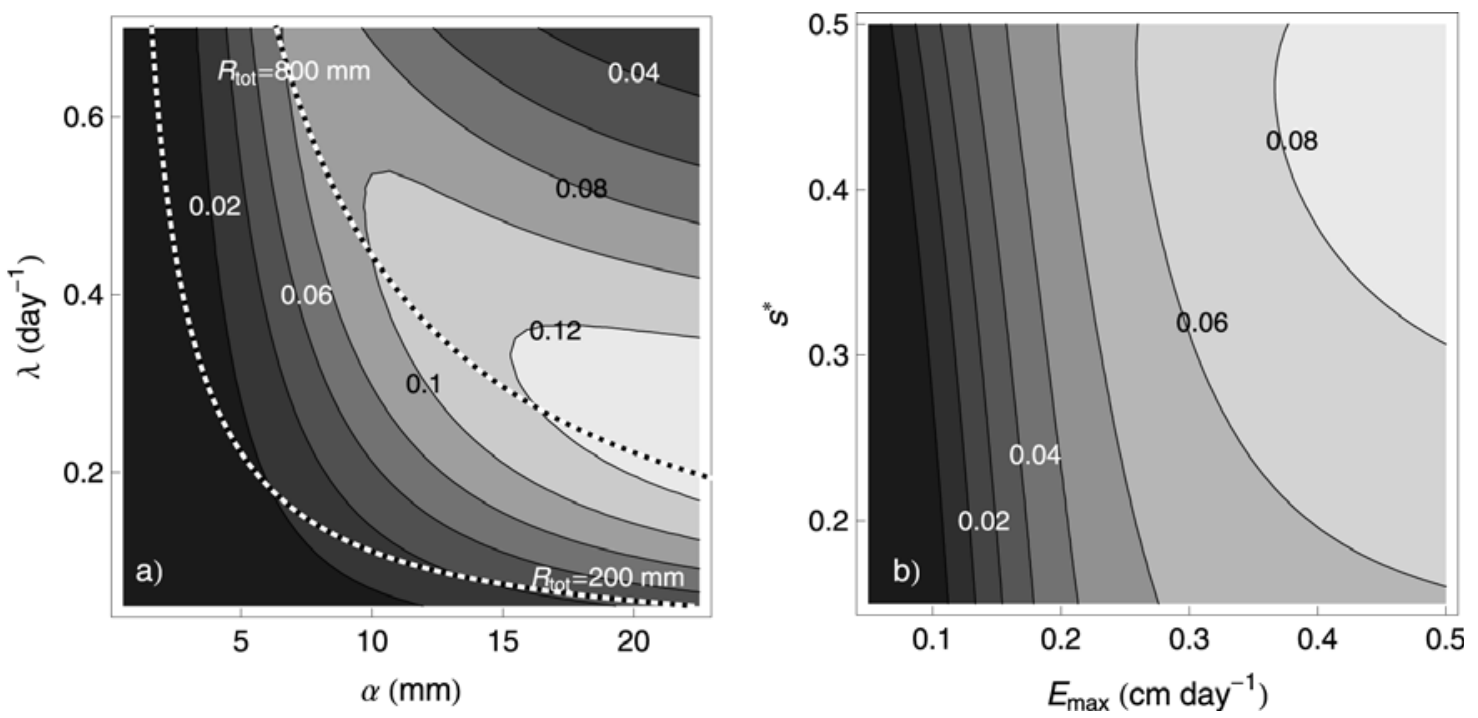

Figure 3. Difference in required irrigation volumes between traditional and microirrigation, $V_{t}-V_{m}$ (units are m of applied water over a 180 day growing season), as a function of (a) rainfall regime (mean event depth, $\alpha$, and frequency of events, $\lambda$ ) and (b) crop water requirements (here represented by maximum transpiration rate, $E_{\max }$, and point of incipient stomatal closure, $\left.s^{*}\right)$. Dashed lines in Figure 3 a represent combinations of $\alpha$ and $\lambda$ leading to the same total precipitation over the growing season, $R_{t o t}$, as indicated. All the other parameters are as in Figure 1.

and duration of each treatment play a role. Microirrigation may last for several days under dry spells, resulting in low frequency of treatments of long duration (and large applied volumes).

[30] When total rainfall is increased while keeping $\alpha$ constant (Figure 4a), the frequency of irrigation decreases monotonically for traditional irrigation, not only because the amount of total precipitation during the growing season is increased, but also because more frequent rainfall events result in soil moisture reaching the threshold $s^{*}$ less often. In the case of microirrigation, the dependence of $\nu_{m}$ on rainfall amounts and frequency is more complex. Maximum irrigation frequency is observed for intermediate $R_{\text {tot }}$ (such maximum occurs at higher values of $R_{\text {tot }}$ for lower mean event depths; not shown). In contrast, low $R_{\text {tot }}$ (i.e., low $\lambda$ ) requires longer periods of continuous irrigation, which translate in lower irrigation frequency, while at the other extreme, frequent rainfall events (and higher total rainfall amounts) result in an overall higher soil moisture and less frequent irrigation applications.

[31] When total growing season rainfall is kept constant while $\alpha$ is increased (Figure 4b), the frequency of irrigation monotonically decreases for microirrigation. In fact, for microirrigation, frequent but small rain events only produce small departures above $s^{*}$ which are quickly nullified by evapotranspiration losses, and this triggers frequent (but short) irrigation periods. In contrast, the rainfall regime has a less marked and opposite impact on traditional irrigation frequency, which, apart for very low event depths, slightly increases with $\alpha$, because frequent but small rainfall events help delay the need for irrigation.

[32] Finally, a sensitivity analysis showed that enhanced plant interception and transpiration rates increase the frequency of traditional irrigation $\nu_{t}$ (not shown). The dependence of $\nu_{m}$ on such parameters is more complex, because the required larger volumes may be provided through either
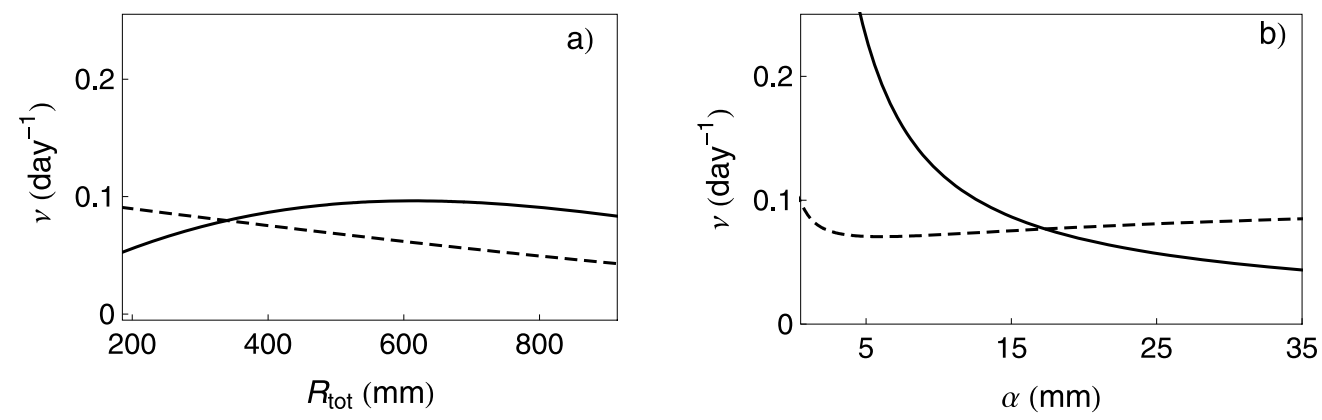

Figure 4. Irrigation frequency requirements under different rainfall amounts and timing, for microirrigation (solid lines) and traditional irrigation (dashed lines), for (a) increasing total rainfall depth but fixed mean event depth $(\alpha=15 \mathrm{~mm})$ and (b) fixed total growing season rainfall depth $\left(R_{t o t}=400 \mathrm{~mm}\right)$. All the other parameters are as in Figure 1. 
more frequent or less frequent (but longer) microirrigation treatments, depending on rainfall pattern (not shown). In fact, $\nu_{m}$ is the frequency of irrigation treatment initiation regardless of its actual duration, so that extended periods of continuous irrigation provide large water volumes, while keeping the treatment frequency low. This is clearly not the case for traditional irrigation where, being each treatment instantaneous (at the daily time scale) and supplying a fixed amount of water, higher water demands are met through an increased irrigation frequency. Also, traditional irrigation is more sensitive to changes in plant water demand than microirrigation (not shown). This sensitivity is also impacted by rainfall amount and timing, but in different ways for the two schemes: for microirrigation, higher rainfall amounts and frequency lead to a stronger dependence of irrigation volumes and frequency on $E_{\max }$, while the opposite is true for traditional irrigation.

\section{Conclusions}

[33] While climatic conditions cannot be controlled, agricultural management may take proactive steps to optimize soil and crop characteristics to improve irrigation efficiency, thus enhancing sustainability and profitability. The presented analytical results clarify the effectiveness of these efforts, and its dependence on the adopted irrigation scheme and rainfall pattern.

[34] When the goal is to maximize crop yield (i.e., stress avoidance irrigation is planned) but water availability is limited, the lower water requirements of microirrigation tend to make it the favorite choice. In fact, stress avoidance irrigation practically ensures the same productivity regardless of the selected irrigation scheme, because transpiration (and thus productivity) is practically constant above stress level (crop productivity is related to seasonal transpiration [e.g., Geerts and Raes, 2009; Payero et al., 2006]). A further potential advantage of microirrigation lies in its ability to minimize lost water, which in turn limits nutrient leaching, runoff and erosion, and groundwater and streamflow pollution. Nevertheless, the limitation of deep percolation might be also a potential drawback when soil salinization is an issue. Under such circumstances, traditional irrigation may be needed, at least once in a while, to facilitate salt flushing from the soil. Moreover, a fine-tuned scheme as microirrigation may be difficult to apply in practice, because of its high costs of installation and maintenance [Brady and Weil, 2002] and the required precise tracking of soil moisture or plant water status, which may be difficult to attain [English et al., 2002; Jones, 2004]. Conversely, for traditional irrigation the amount of water to be supplied at each treatment does not depend on the potentially fluctuating transpiration rate, but only on soil water status, thus making such scheme easier to apply in practice.

[35] More importantly, it appears from our results (e.g., Figure 3 ) that the extent of the water savings achieved with microirrigation depends on rainfall regime, and plant characteristics, and may become irrelevant under some conditions. Thus, even remaining within the ambit of stress avoidance irrigation, it is clear that choosing the most profitable, practical and sustainable scheme of irrigation depends on a variety of issues. All of these issues are subordinated to quantifying probabilistically the vagaries of the hydroclimatic regime. The analytical solutions provided here are a first step in this direction.

\section{Appendix A: Evolution of Soil Moisture Probability Density Function}

[36] In this section, the steady state soil moisture pdf's for rain-fed agriculture (i.e., natural conditions), micro- and traditional irrigation are obtained for a generic normalized loss function $\rho(s)=E T(s) / n Z_{r}$. The specific case of piecewise linear loss function (equation (2)) is discussed in Appendix B.

\section{A1. Rain-Fed Agriculture}

[37] The evolution of soil moisture pdf for rain-fed agriculture can be described by the following master or differential Chapman-Kolmogorov equation:

$$
\frac{\partial}{\partial t} p(s, t)=\frac{\partial}{\partial s}[\rho(s) p(s, t)]-\lambda^{\prime} p(s, t)+\lambda^{\prime} \int_{0}^{s} p(u, t) f(s-u, u) d u
$$

where $f(y, s)$ is the pdf of the soil moisture jumps due to the difference between the instantaneous rainfall and the runoff and percolation events, i.e., $f(y, s)=\gamma e^{-\gamma y}+\delta\left(y-s_{1}+s\right)$ $e^{-\gamma\left(s_{1}-s\right)}$ [Porporato et al., 2004; Rodriguez-Iturbe and Porporato, 2004]. Because of our simplified treatment of runoff and deep infiltration, the soil moisture process is bounded at $s_{1}$. Equation (A1) can also be written in the form [Daly and Porporato, 2006b]

$$
\frac{\partial}{\partial t} p(s, t)=-\frac{\partial}{\partial s} J(s, t)
$$

where the probability current $J(s, t)$, which represents the net number of soil moisture trajectories upcrossing a level $s$ per unit time, is

$$
J(s, t)=-\rho(s) p(s, t)+\lambda^{\prime} \int_{0}^{s} e^{-\gamma(s-u)} p(u, t) d u .
$$

A general solution of either equation (A1) or equations (A2) and (A3) presents serious mathematical difficulties. We focus here on stochastic steady state conditions, i.e., $\partial p(s, t) / \partial t=0$, in which case the probability current is constant (see equation (A2)). In particular, for rain-fed agriculture, $J(s)=0$, and the effect of the bound is reduced to a renormalization of the steady state pdf in the unbounded case [Rodriguez-Iturbe et $a l ., 1999]$. The pdf of $s$, reported in equation (3), is obtained by multiplying equation (A3) by $e^{\gamma s}$, differentiating with respect to $s$, and solving the resulting first-order linear differential equation (see Rodriguez-Iturbe et al. [1999] for details). The normalization constant $C$ is obtained by imposing

$$
\int_{0}^{s_{1}} p(u) d u=1
$$

The cumulative probability function,

$$
P(s)=\int_{0}^{s} p(u) d u
$$



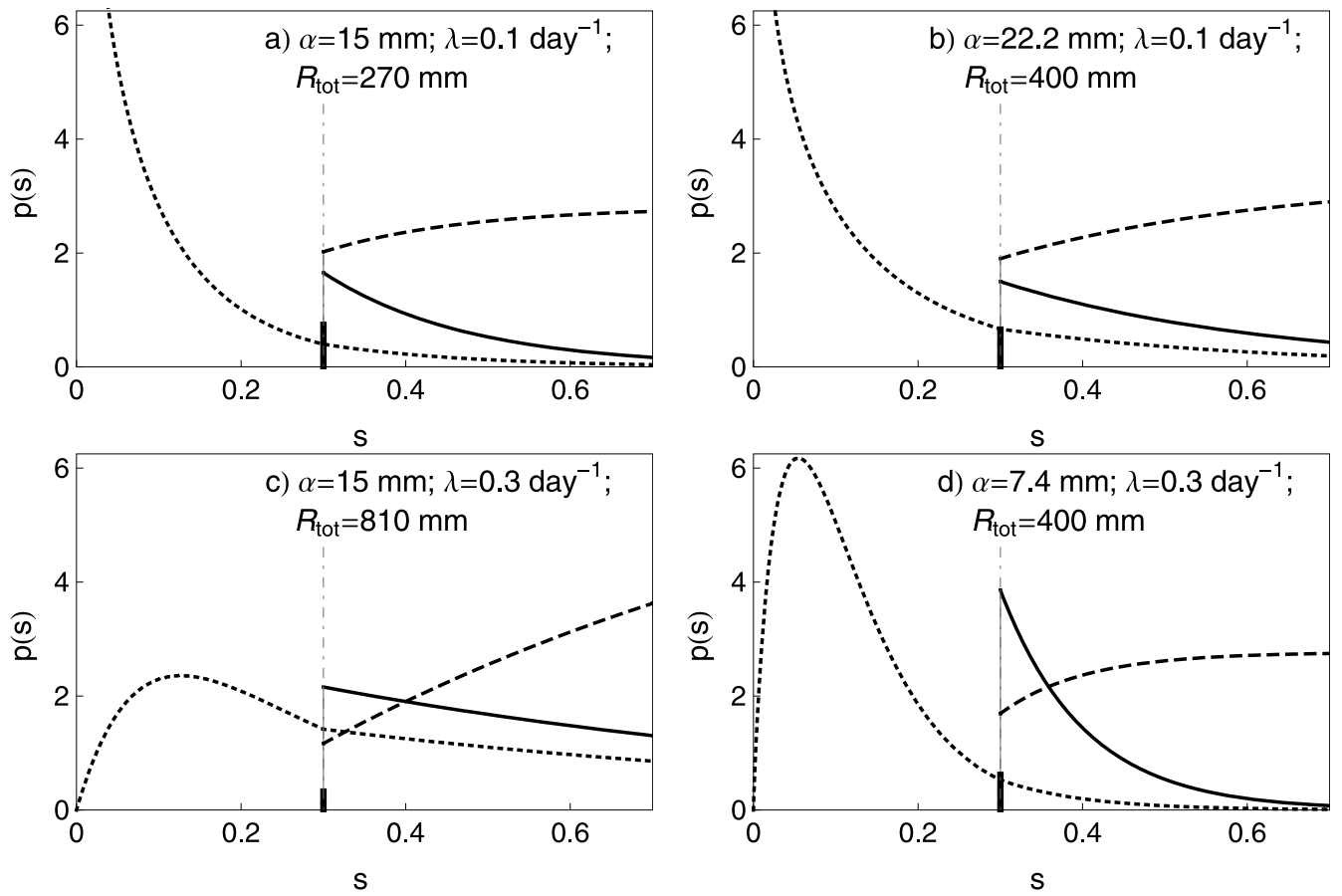

Figure A1. Examples of steady state probability density functions of soil moisture under different rainfall amounts and patterns, relative to the two irrigation schemes (microirrigation is denoted by solid lines and traditional irrigation is denoted by long-dashed lines); the case of no irrigation is plotted for reference (short-dashed lines). (a and c) Constant mean event depth ( $\alpha=15 \mathrm{~mm}$, with increasing $\lambda$ and $R_{\text {tot }}$ as indicated). (b and d) Constant total growing season precipitation $\left(R_{t o t}=400 \mathrm{~mm}\right.$, with different combinations of $\lambda$ and $\alpha$, as indicated). All the other parameters are as in Figure 1. The thick solid lines represent the atom of probabilities for the microirrigation (not to scale). The vertical dash-dotted lines indicate $s^{*}$.

gives the average fraction of time spent by the process below $s$ during a homogeneous growing season, as a function of soil, climate and vegetation characteristics.

\section{A2. Microirrigation}

[38] Microirrigation exactly compensates the losses at a given $s^{*}$. Mathematically, it is thus equivalent to setting the overall loss function $\rho(s)$ to zero for $s \leq s^{*}$. Thus, formally the problem becomes equivalent to a Takacs waiting time process upper bounded at $s_{1}$ [Cox and Miller, 2001, p. 240; Rodriguez-Iturbe and Porporato, 2004], and the master equation is more conveniently solved by splitting it into a part for the continuous distribution $p_{m}(s)$

$$
\begin{aligned}
\frac{\partial}{\partial t} p_{m}(s, t)= & \frac{\partial}{\partial s}\left[\rho(s) p_{m}(s, t)\right]-\lambda^{\prime} p_{m}(s, t) \\
& +\lambda^{\prime} \int_{s^{*}}^{s} p_{m}(u, t) f(s-u, u) d u+\lambda^{\prime} p_{0}(t) f\left(s-s^{*}, s^{*}\right)
\end{aligned}
$$

and a part for the atom of probability in $s^{*}$

$$
\frac{d}{d t} p_{0}(t)=-\lambda^{\prime} p_{0}(t)+\rho\left(s^{*}\right) p_{m}\left(s^{*}, t\right) .
$$

Apart from a multiplication constant, (A6) admits the same solution as (A1). In fact, the relative fraction of time spent by the process between any two soil moisture levels is not changed by the presence of the atom of probability in $s^{*}$. Hence, the continuous part of the pdf, reported in (4), has the same form of the one obtained for rain-fed agriculture in the case of $s \geq s^{*}$. Only the normalization constant is altered by the presence of the atom of probability. To obtain the latter, we first note that, at steady state, (A7) becomes an equality between the rate of upcrossings and that of downcrossings at $s^{*}$ (see equation (7)), i.e., $\lambda^{\prime} p_{0}=\rho\left(s^{*}\right) p_{m}\left(s^{*}\right)$, which gives

$$
p_{0}=\frac{\rho\left(s^{*}\right) p_{m}\left(s^{*}\right)}{\lambda^{\prime}}=\frac{C_{m}}{\lambda^{\prime}} e^{-\gamma s^{*}} .
$$

The normalization constant $C_{m}$ can be obtained by imposing

$$
1-p_{0}=\int_{s^{*}}^{s_{1}} p(u) d u .
$$

\section{A3. Traditional Irrigation}

[39] Differently from microirrigation, the massive water application typical of traditional irrigation results in a loss of trajectories at $s^{*}$ and their reinjection at $s_{1}$. This alters the balance of upcrossings and downcrossings, so that the probability current $J$ is no longer zero. Evaluating equation (A3) at $s=s^{*}$, it is easy to show that $J$ is constant and equal to 
$J^{*}=-\rho\left(s^{*}\right) p\left(s^{*}\right)$. Hence, the pdf of soil moisture for traditional irrigation is described by the following equation:

$$
J^{*}=-\rho(s) p_{t}(s)+\lambda^{\prime} \int_{s^{*}}^{s} e^{-\gamma(s-u)} p_{t}(u) d u
$$

where the quantities referring to traditional irrigation are indicated with the subscript $t$. Also, $-J^{*}$ is equal to the frequency of downcrossing (and upcrossing) of $s^{*}$. Multiplying (A10) by $e^{\gamma s}$ and differentiating with respect to $s$ yield a firstorder linear differential equation, the solution of which is the desired probability density function of soil moisture for traditional irrigation (equation (6)). No atom of probability forms at the boundaries $s^{*}$ and $s_{1}$, as at neither ends does soil moisture process spend a finite amount of time. Combining the obtained pdf with (A10), it is easy to show that $J^{*}=C_{t}$ when the lower limit of integration in (A10) is set to $s^{*}$. The normalization constant $C_{t}$ is such that

$$
\int_{s^{*}}^{s_{1}} p_{t}(u) d u=1
$$

\section{Appendix B: Soil Moisture Probability Density Function for Piecewise Linear Loss Function}

[40] Assuming piecewise linear losses (equation (2)), with appropriate substitutions and integrations, the steady state pdf's of soil moisture can be obtained from the general equations reported in the text (equations (3)-(6)).

[41] For rain-fed agriculture, the pdf of soil moisture (equation (3)) becomes

$$
p(s)= \begin{cases}\frac{C}{\eta}\left(\frac{s}{s^{*}}\right)^{\frac{\lambda^{\prime}}{\eta} s^{*}-1} e^{-\gamma s}, & 0 \leq s<s^{*} \\ \frac{C}{\eta} e^{-\frac{\lambda^{\prime}}{\eta} s^{*}} e^{-s\left(\gamma-\frac{\lambda^{\prime}}{\eta}\right)}, & s^{*} \leq s \leq s_{1} .\end{cases}
$$

The normalizing constant $C$ is obtained by imposing equation (A4), and reads

$$
\begin{aligned}
C= & \left\{\frac{e^{-\gamma s^{*}}-e^{-\gamma s_{1}+\frac{\lambda^{\prime}}{\eta}\left(s_{1}-s^{*}\right)}}{\eta \gamma-\lambda^{\prime}}\right. \\
& \left.+\frac{s^{*}}{\eta}\left(\gamma s^{*}\right)^{-\frac{\lambda^{\prime}}{\eta} s^{*}}\left[\Gamma\left(\frac{\lambda^{\prime}}{\eta} s^{*}\right)-\Gamma\left(\frac{\lambda^{\prime}}{\eta} s^{*}, \gamma s^{*}\right)\right]\right\}^{-1},
\end{aligned}
$$

where $\Gamma\left(\frac{\lambda^{\prime}}{\eta} s^{*}, \gamma s^{*}\right)=\int_{*}^{\infty} u^{\frac{\lambda^{\prime}}{\eta} s^{*}-1} e^{u} d u$ is the incomplete gamma function [Abramowitz and Stegun, 1965].

[42] For microirrigation the pdf of $s$ is formally equivalent to the case of rain-fed agriculture (equation (B1)) for $s \geq s^{*}$, i.e.,

$$
p_{m}(s)=\frac{C_{m}}{\eta} e^{-\frac{\lambda^{\prime}}{\eta} s^{*}} e^{-s\left(\gamma-\frac{\lambda^{\prime}}{\eta}\right)} .
$$

The atom of probability, obtained by solving equation (A7), has the same form of the general solution (equation (5))

$$
p_{0}=\frac{C_{m}}{\lambda^{\prime}} e^{-\gamma s^{*}}
$$

while the normalization constant is obtained by imposing equation (A9) and reads

$$
C_{m}=\frac{\eta \gamma-\lambda^{\prime}}{\eta \gamma \lambda^{\prime}-1 e^{-\gamma s^{*}}-e^{-\gamma s_{1}} e^{\frac{\lambda^{\prime}}{\eta}\left(s_{1}-s^{*}\right)}} .
$$

Conversely, for traditional irrigation the pdf of $s$ becomes

$$
p_{t}(s)=\frac{C_{t}}{\eta \gamma-\lambda^{\prime}}\left[\frac{\lambda^{\prime}}{\eta} e^{-\left(\gamma-\frac{\lambda^{\prime}}{\eta}\right)\left(s-s^{*}\right)}-\gamma\right]
$$

where

$$
C_{t}=\left(\eta \gamma-\lambda^{\prime}\right)\left\{\frac{\lambda^{\prime}}{\eta \gamma-\lambda^{\prime}}\left[1-e^{-\left(\gamma-\frac{\lambda^{\prime}}{\eta}\right)\left(s_{1}-s^{*}\right)}\right]-\gamma\left(s_{1}-s^{*}\right)\right\}^{-1} .
$$

[43] Some examples of the obtained pdf's are shown in Figure A1, under different rainfall conditions. The pdfs have drastically different shapes and modes. The mode lies below $s^{*}$ for rain-fed agriculture, at $s^{*}$ for microirrigation, and at $s_{1}$ for traditional irrigation. However, under higher total rainfall depths, the mode can shift above $s^{*}$ for both rain-fed conditions and microirrigation. Furthermore, as expected, irrigation results in higher probabilities at higher soil moisture levels. This fact is particularly evident in the case of traditional irrigation, because it provides larger irrigation volumes (see section 3.1). The impact of rainfall regime on soil moisture pdf is assessed by analyzing the following two cases: (1) increasing the total rainfall per growing season $\langle R\rangle T_{\text {seas }}=\alpha \lambda T_{\text {seas }}$ by changing storm frequency, $\lambda$, while keeping $\alpha$ fixed (Figures A1a and A1c) and (2) keeping fixed total amount of rainfall during the growing season, while altering $\alpha$ and $\lambda$ (Figures A1b and A1d). In the first case (Figures Ala and A1c), an increase in storm frequency results in a shift in the mode of the probability distribution toward higher $s$, a clear consequence of the increased total seasonal precipitation. The shape of the distribution is also modified. For rain-fed and microirrigated agriculture, an increase in $\lambda$ and the consequent increase in total precipitation result in a more uniform distribution of $s$, while for traditional irrigation the more frequent storms require fewer irrigation treatments and increase the time spent at soil moisture levels near $s_{1}$. The case of constant total precipitation (Figures A1b and A1d) clarifies the impact of rainfall timing and amounts. Infrequent but large events tend to produce low soil moisture levels because of the increased losses by percolation and deep infiltration (Figure A1b); similarly, very frequent but shallow events favor canopy interception with a consequent reduction of total effective rainfall (Figure A1d). For microirrigation (solid lines), smaller but frequent events contribute to maintain soil moisture not far above $s^{*}$ (Figure A1d), while infrequent events delivering higher amounts of water result in a more uniform probability distribution between $s^{*}$ and $s_{1}$ (Figure A1b). Conversely, for traditional irrigation frequent but small events counteract the impact of irrigation water applications, which would increase the time spent by the process at soil moisture levels near $s_{1}$, thus increasing the time the system spends at intermediate soil moisture levels (Figure A1d, long-dashed line). 
[44] Acknowledgments. This research was supported by the U.S. National Science Foundation under grant EAR-0628432, by the U.S. Department of Energy through the Office of Biological and Environmental Research (BER) Terrestrial Carbon Processes (TCP) program (NICCR grant DE-FC02-06ER64156), and by a collaboration grant from the U.S. Department of Agriculture, Agricultural Research Service, Temple, Texas. A.P. gratefully acknowledges the support of the Landolt \& Cie Chair "Innovative strategies for a sustainable future" at the École Polytechnique Fédérale de Lausanne, Lausanne, Switzerland. We thank A. J. Guswa, P. Perona, and S. Schymanski for their comments on an earlier version of the manuscript.

\section{References}

Abramowitz, M., and I. A. Stegun (1965), Handbook of Mathematical Functions, 1046 pp., Dover, New York.

Böhlke, J. K. (2002), Groundwater recharge and agricultural contamination, Hydrogeol. J., 10, 153-179, doi:10.1007/s10040-001-0183-3.

Brady, N. C., and R. R. Weil (2002), The Nature and Properties of Soils, 13th ed., 960 pp., Prentice Hall, Upper Saddle River, N. J.

Bras, R. L., and J. R. Cordova (1981), Intraseasonal water allocation in deficit irrigation, Water Resour. Res., 17, 866-874, doi:10.1029/ WR017i004p00866.

Bras, R. L., and D. J. Seo (1987), Irrigation control in the presence of salinity: Extended linear quadratic approach, Water Resour. Res., 23, 1153-1161, doi:10.1029/WR023i007p01153.

Chalmers, D. J., et al. (1981), Control of peach-tree growth and productivity by regulated water-supply, tree density, and summer pruning, J. Am. Soc. Hortic. Sci., 106, 307-312.

Cox, D. R., and H. D. Miller (2001), The Theory of Stochastic Processes, 398 pp., Chapman and Hall, Boca Raton, Fla.

Daly, E., and A. Porporato (2006a), Impact of hydroclimatic fluctuations on the soil water balance, Water Resour. Res., 42, W06401, doi:10.1029/ 2005 WR004606.

Daly, E., and A. Porporato (2006b), State-dependent fire models and related renewal processes, Phys. Rev. E, 74, 041112.1-041112.9.

Daly, E., et al. (2008), A stochastic model for daily subsurface $\mathrm{CO}_{2}$ concentration and related soil respiration, Adv. Water Resour., 31, 987-994, doi:10.1016/j.advwatres.2008.04.001.

English, M. (1990), Deficit irrigation. Part I. Analytical framework, J. Irrig. Drain. Eng., 116, 399-412, doi:10.1061/(ASCE)07339437(1990)116:3(399).

English, M. J., et al. (2002), A paradigm shift in irrigation management, J. Irrig. Drain. Eng., 128, 267-277, doi:10.1061/(ASCE)0733-9437 (2002)128:5(267).

Fereres, E., and M. A. Soriano (2007), Deficit irrigation for reducing agricultural water use, J. Exp. Bot., 58, 147-159, doi:10.1093/jxb/erl165.

Geerts, S., and D. Raes (2009), Deficit irrigation as an on-farm strategy to maximize crop water productivity in dry areas, Agric. Water Manage., 96, 1275-1284, doi:10.1016/j.agwat.2009.04.009.

Georgiou, P. E., and D. M. Papamichail (2008), Optimization model of an irrigation reservoir for water allocation and crop planning under various weather conditions, Irrig. Sci., 26, 487-504, doi:10.1007/s00271-0080110-7.
Hillel, D. (2004), Introduction to Environmental Soil Physics, 494 pp., Elsevier Acad., Amsterdam.

Hsiao, T. C. (1973), Plant responses to water stress, Annu. Rev. Plant Physiol. Plant Mol. Biol., 24, 519-570.

Jones, H. G. (2004), Irrigation scheduling: Advantages and pitfalls of plantbased methods, J. Exp. Bot., 55, 2427-2436, doi:10.1093/jxb/erh213.

Jury, W. A., and H. J. Vaux (2007), The emerging global water crisis: Managing scarcity and conflict between water users, Adv. Agron., 95, 1-76, doi:10.1016/S0065-2113(07)95001-4.

Kalapos, T., et al. (1996), Effect of soil drying on growth, biomass allocation and leaf gas exchange of two annual grass species, Plant Soil, 185, 137-149, doi:10.1007/BF02257570.

Laio, F., et al. (2001), Plants in water-controlled ecosystems: Active role in hydrologic processes and response to water stress: Part II. Probabilistic soil moisture dynamics, Adv. Water Resour., 24, 707-723, doi:10.1016/S0309-1708(01)00005-7.

Milly, P. C. D. (2001), A minimalist probabilistic description of root zone soil water, Water Resour. Res., 37, 457-463, doi:10.1029/ 2000WR900337.

Morison, J. I. L., and R. M. Gifford (1984), Plant growth and water use with limited water-supply in high $\mathrm{CO}_{2}$ concentrations. Part I. Leaf area, water use and transpiration, Aust. J. Plant Physiol., 11, 361-374, doi:10.1071/PP9840361.

Payero, J. O., et al. (2006), Yield response of corn to deficit irrigation in a semiarid climate, Agric. Water Manage., 84, 101-112, doi:10.1016/j. agwat.2006.01.009.

Porporato, A., et al. (2001), Plants in water-controlled ecosystems: Active role in hydrologic processes and response to water stress: Part III. Vegetation water stress, Adv. Water Resour., 24, 725-744, doi:10.1016/S0309-1708(01)00006-9.

Porporato, A., et al. (2004), Soil water balance and ecosystem response to climate change, Am. Nat., 164, 625-632, doi:10.1086/424970.

Protopapas, A. L., and A. P. Georgakakos (1990), An optimal-control method for real-time irrigation scheduling, Water Resour. Res., 26, 647-669.

Rigby, J. R., and A. Porporato (2006), Simplified stochastic soil-moisture models: A look at infiltration, Hydrol. Earth Syst. Sci., 10, 861-871.

Rodriguez-Iturbe, I., and A. Porporato (2004), Ecohydrology of WaterControlled Ecosystems: Soil Moisture and Plant Dynamics, Cambridge Univ. Press, Cambridge, U. K.

Rodriguez-Iturbe, I., et al. (1999), Probabilistic modelling of water balance at a point: The role of climate, soil and vegetation, Proc. R. Soc. London A, 455, 3789-3805.

Zhang, H. P., and T. Oweis (1999), Water-yield relations and optimal irrigation scheduling of wheat in the Mediterranean region, Agric. Water Manage., 38, 195-211, doi:10.1016/S0378-3774(98)00069-9.

A. Porporato and G. Vico, Department of Civil and Environmental Engineering, Duke University, 119 Hudson Hall, Research Dr., P.O. Box 90287, Durham, NC 27708, USA. (amilcare@duke.edu; giulia.vico@ duke.edu) 